\title{
Improving color uniformity and color rending index of remote-phosphor packaging white LEDs by co-doping $\mathrm{SiO}_{2}$ and $\mathrm{Sr}_{2} \mathbf{S i}_{5} \mathbf{N}_{8}: \mathbf{E u}^{2+}$ particles
}

\author{
Tran HoAng Quang Minh ${ }^{1, *}$, Nguyen HuU Khanh Nhan ${ }^{1}$, NGuYen DoAn Quoc AnH ${ }^{2}$, \\ TRAN THANH NAM ${ }^{1}$, HSIAO-Yi LEE ${ }^{1,3}$ \\ ${ }^{1}$ Optoelectronics Research Group, Faculty of Electrical and Electronics Engineering, \\ Ton Duc Thang University, Ho Chi Minh City, Vietnam \\ ${ }^{2}$ Power System Optimization Research Group, Faculty of Electrical and Electronics Engineering, \\ Ton Duc Thang University, Ho Chi Minh City, Vietnam \\ ${ }^{3}$ Department of Electrical Engineering, National Kaohsiung University of Applied Sciences, Kaohsiung City, Taiwan
}

\begin{abstract}
Based on some advantageous properties, such as fast response time, environment friendliness, small size, long lifetime, and high efficiency, white LEDs are increasingly used in common illumination applications. In this research, by co-doping of redemitting $\mathrm{Sr}_{2} \mathrm{Si}_{5} \mathrm{~N}_{8}: \mathrm{Eu}^{2+}$ phosphor and adding $\mathrm{SiO}_{2}$ particles to yellow-emitting YAG:Ce phosphor compounds, a new approach for improving color uniformity and color rending index of remote-phosphor structure white LEDs is proposed and demonstrated. The obtained results clearly indicate that the color rendering index (CRI) and color uniformity $(\Delta C C T)$ significantly depend on $\mathrm{Sr}_{2} \mathrm{Si}_{5} \mathrm{~N}_{8}: \mathrm{Eu}^{2+}$ concentration. The results provide a potential practical solution for manufacturing remote-phosphor white LEDs (RP-WLEDs) in the near future.
\end{abstract}

Keywords: white LEDs (WLEDs); remote-phosphor white LEDs (RP-WLEDs); $\mathrm{SiO}_{2} ; \mathrm{Sr}_{2} \mathrm{Si}_{5} \mathrm{~N}_{8}: E u^{2+}$ phosphor; color rendering index, color uniformity

\section{Introduction}

Nowadays, light-emitting diodes (LEDs) are popularly used, with a rapid progress, for lighting applications such as traffic signals, signage, vehicle lighting, and liquid crystal display backlight. They became a critical illumination source because of their high efficiency, long lifetime, low energy consumption, low cost, and environmental friendliness compared to conventional lighting sources $[1,2]$. Up to date, there are three methods to obtain white light emission in white light-emitting diodes (WLEDs). The most common method is the phosphor-converted WLEDs technique. The second method involves mixing the light of different colors generated by red, green, and blue chips. The last method includes the use of organic phosphors or some other novel phosphors

*E-mail: tranhoangquangminh@tdt.edu.vn with suitable emission color and high energy to obtain white light. Advantages of the first method for the generation of white light are pure fabrication, low cost, high conversion efficiency compared to three individual red, green, and blue LEDs mixing, and ultraviolet LEDs (UV-LEDs) exciting multiple phosphors [3]. Due to this situation, many recent studies have been focused on enhancement the lighting properties of WLEDs fabricated using the first method. Lighting properties of WLEDs have been improved in various ways: by using phosphors $\mathrm{Sr}_{1-\mathrm{x}} \mathrm{Ba}_{\mathrm{x}} \mathrm{Si}_{2} \mathrm{O}_{2} \mathrm{~N}_{2}: \mathrm{Eu}^{2+}(\mathrm{x}=0-1)$ [4], by $\beta-\mathrm{SiAlON}: \mathrm{Yb}^{2+}$ phosphor [5], by varying phosphor materials and packaging structures [6], by red-emitting phosphor $\mathrm{Li}_{2} \mathrm{SrSiO}_{4}: \mathrm{Eu}^{3+}, \mathrm{Sm}^{3+}$ [7], or by adding $\mathrm{SiO}_{2}$ to YAG:Ce phosphor compound of WLEDs [8, 9]. However, these methods are focused on improving the lighting properties of WLEDs with conformal and in-cup phosphor package by adding only one diffusive particle into 
the phosphor compound or without adding anything. On another hand, the remote phosphor structure of WLEDs is a structure in which a phosphor is moved far away from the LED chip. This structure could significantly reduce the probability of absorption of the re-emitted light by the WLEDs chip and this could improve the phosphor efficiency. With these improvements, the remote phosphor structure of WLEDs seems to be a recommended solution for the manufacture of WLEDs [10-13]. However, very few works have improved the lighting performance of WLEDs with remote phosphor structure by mixing two or more diffusive particles into a phosphor compound. It is the remaining gap, which could be filled by this research work.

In last decade, $\mathrm{SiN}_{4}$-based covalent nitride materials such as $\mathrm{M}_{2} \mathrm{Si}_{5} \mathrm{~N}_{8}: \mathrm{Eu}^{2+}$ and $\mathrm{MAlSiN}_{3}: \mathrm{Eu}^{2+}$ $(\mathrm{M}=\mathrm{Ca}, \mathrm{Sr}, \mathrm{Ba})$ have been extensively considered as excellent materials for LEDs technology. Among these phosphors, $\mathrm{Sr}_{2} \mathrm{Si}_{5} \mathrm{~N}_{8}$ : $\mathrm{Eu}^{2+}$ has shown high performance of LED packages with excellent emission characteristics under a blue excitation wavelength of $450 \mathrm{~nm}$ and a uniform particle size distribution [14-16]. In this research, an innovative method consisting in mixing $\mathrm{SiO}_{2}$ and $\mathrm{Sr}_{2} \mathrm{Si}_{5} \mathrm{~N}_{8}: \mathrm{Eu}^{2+}$ phosphor particles into the YAG:Ce phosphor of RP-WLEDs to improve their color uniformity and CRI has been presented and investigated. By fixing the concentration of $\mathrm{SiO}_{2}$ particles at $5 \%$, the influence of the concentration of $\mathrm{Sr}_{2} \mathrm{Si}_{5} \mathrm{~N}_{8}: \mathrm{Eu}^{2+}$ phosphor particles on $\triangle \mathrm{CCT}$ and CRI of WLEDs was analyzed and demonstrated. The results indicate that $\triangle \mathrm{CCT}$ and CRI could be significantly increased by using $\mathrm{SiO}_{2}$ and $\mathrm{Sr}_{2} \mathrm{Si}_{5} \mathrm{~N}_{8}: \mathrm{Eu}^{2+}$ phosphor.

\section{Physical simulation model and mathematical analysis}

In this section, $8500 \mathrm{~K}, 7700 \mathrm{~K}$, and $7000 \mathrm{~K} \mathrm{RP}-$ WLEDs have been simulated by using the commercial LightTools 8.1.0 software based on the Monte Carlo ray-tracing method. The physical model of WLEDs used for simulations is shown in Fig. 1. In this physical model, the reflector has $8 \mathrm{~mm}$ bottom length, $2.07 \mathrm{~mm}$ height, and $9.85 \mathrm{~mm}$ length.
The remote phosphor layer with a fixed thickness of $0.08 \mathrm{~mm}$ covers nine LED chips. Each LED chip has a $1.14 \mathrm{~mm}$ square base and a $0.15 \mathrm{~mm}$ height. The radiant flux of each blue chip is $1.16 \mathrm{~W}$ at a wavelength of $455 \mathrm{~nm}$. At a concentration of $\mathrm{SiO}_{2}$ particles in the phosphor compound fixed at $5 \%$, the concentration of $\mathrm{Sr}_{2} \mathrm{Si}_{5} \mathrm{~N}_{8}$ : $\mathrm{Eu}^{2+}$ phosphor particles is changed continuously from $4 \%$ to $28 \%$. The optical properties of $\mathrm{SiO}_{2}$ and $\mathrm{Sr}_{2} \mathrm{Si}_{5} \mathrm{~N}_{8}: \mathrm{Eu}^{2+}$ phosphor particles are simulated using the LightTools 8.1.0 software. The refractive index of the diffusors, such as $\mathrm{SiO}_{2}$ and $\mathrm{Sr}_{2} \mathrm{Si}_{5} \mathrm{~N}_{8}: \mathrm{Eu}^{2+}$ phosphors, are chosen as 1.46 and 1.80 , respectively. The $\mathrm{SiO}_{2}$ particles are assumed to be spherical and have an average radius of $3 \mu \mathrm{m}$ in Mie simulation. The average radius of the phosphor particles is $7.25 \mu \mathrm{m}$ and refractive index is 1.83 at all light wavelengths. The silicone glue has the refractive index of 1.5. In this model, in order to fix the average CCT value, the diffusional particle density is necessary to vary. Finally, the weight percentage of the yellow-emitting YAG:Ce phosphor needs to be reduced to maintain the average CCT value when the weight percentage of the diffusers is increased.

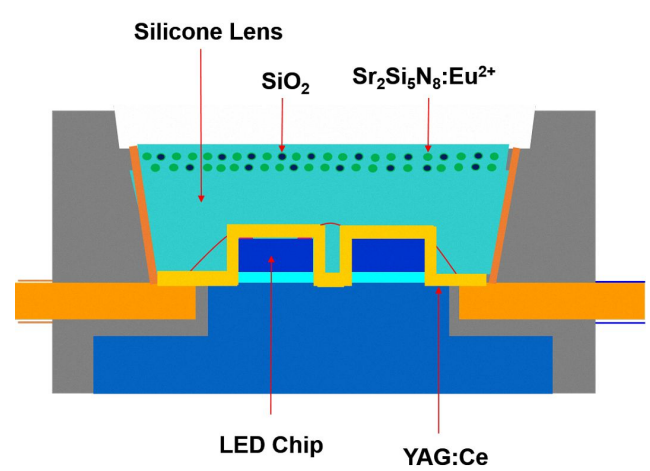

Fig. 1. Physical structure of WLEDs with remote phosphor layer.

Applying Mie theory [17, 18], the scattering coefficient $\mu_{\mathrm{sca}}(\lambda)$, anisotropy factor $g(\lambda)$, and reduced scattering coefficient $\delta_{\text {sca }}(\lambda)$ could be formulated by the following expressions:

$$
\mu_{s c a}(\lambda)=\int N(r) C_{s c a}(\lambda, r) d r
$$




$$
\begin{gathered}
g(\lambda)=2 \pi \iint_{-1}^{1} p(\theta, \lambda, r) f(r) \cos \theta d \cos \theta d r \\
\delta_{s c a}=\mu_{s c a}(1-g)
\end{gathered}
$$

In these equations, $\mathrm{N}(\mathrm{r})$ indicates the distribution density of diffusional particles $\left[\mathrm{mm}^{3}\right] . \mathrm{C}_{\mathrm{sca}}$ is the scattering cross sections $\left[\mathrm{mm}^{2}\right], \mathrm{r}$ is the radius of diffusional particles $[\mu \mathrm{m}], \mathrm{p}(\theta, \lambda, \mathrm{r})$ is the phase function, $\lambda$ is the light wavelength $[\mathrm{nm}], \theta$ is the scattering angle $\left[{ }^{\circ}\right]$, and $f(r)$ is the size distribution function of the diffuser in the phosphorous layer. Furthermore, $f(r)$ and $N(r)$ could be given by:

$$
\begin{gathered}
f(r)=f_{\text {dif }}(r)+f_{\text {phos }}(r) \\
N(r)=N_{\text {dif }}(r)+N_{\text {phos }}(r)=K_{N} \cdot\left[f_{\text {dif }}(r)+f_{\text {phos }}(r)\right]
\end{gathered}
$$

$\mathrm{N}(\mathrm{r})$ is composed of the diffusive particle number density $\mathrm{N}_{\text {dif }}(\mathrm{r})$ and the phosphor particle number density $\mathrm{N}_{\text {phos }}(r)$. In these equations, $f_{\text {dif }}(r)$ and $f_{\text {phos }}(r)$ are the size distribution function data of the diffusor and phosphor particle. Here, $\mathrm{K}_{\mathrm{N}}$ is the number of the unit diffusor for one diffuser concentration and can be calculated by the following equation:

$$
c=K_{N} \int M(r) d r
$$

where $M(r)$ is the mass distribution of the unit diffuser and can be proposed by the below equation:

$$
M(r)=\frac{4}{3} \pi r^{3}\left[\rho_{\text {dif }} f_{\text {dif }}(r)+\rho_{\text {phos }} f_{\text {phos }}(r)\right]
$$

Here, $\rho_{\text {diff }}(r)$ and $\rho_{\text {phos }}(r)$ are the density of diffuser and phosphor crystal.

In Mie theory, $\mathrm{C}_{\mathrm{sca}}$ can be obtained by the following expression:

$$
C_{s c a}=\frac{2 \pi}{k^{2}} \sum_{0}^{\infty}(2 n-1)\left(\left|a_{n}\right|^{2}+\left|b_{n}\right|^{2}\right)
$$

where $k=2 \pi / \lambda$, and $a_{n}$ and $b_{n}$ are calculated by:

$$
a_{n}(x, m)=\frac{\psi_{n}^{\prime}(m x) \psi_{n}(x)-m \psi_{n}(m x) \psi_{n}{ }^{\prime}(x)}{\psi_{n}^{\prime}(m x) \xi_{n}(x)-m \psi_{n}(m x) \xi_{n}^{\prime}(x)}
$$

$$
b_{n}(x, m)=\frac{m \psi_{n}^{\prime}(m x) \psi_{n}(x)-\psi_{n}(m x) \psi_{n}^{\prime}(x)}{m \psi_{n}^{\prime}(m x) \xi_{n}(x)-\psi_{n}(m x) \xi_{n}^{\prime}(x)}
$$

where $\mathrm{x}=\mathrm{k} \cdot \mathrm{r}, \mathrm{m}$ is the refractive index, and $\psi_{\mathrm{n}}(\mathrm{x})$ and $\xi_{n}(x)$ are the Riccati-Bessel function.

In RP-WLEDs, the relative refractive indices of diffusor $-\mathrm{m}_{\mathrm{dif}}$ and phosphor $-\mathrm{m}_{\mathrm{phos}}$ in the silicone can be calculated by $\mathrm{m}_{\text {dif }}=\mathrm{n}_{\text {dif }} / \mathrm{n}_{\text {sil }}$ and $m_{\text {phos }}=n_{\text {phos }} / n_{\text {sil }}$. Then the phase function $p(\theta, \lambda, r)$ can be expressed by the below equation:

$$
p(\theta, \lambda, r)=\frac{4 \pi \beta(\theta, \lambda, r)}{k^{2} C_{s c a}(\lambda, r)}
$$

where $\beta(\theta, \lambda, r) S_{1}(\theta)$ and $S_{2}(\theta)$ are calculated by equations 12 to 14 :

$$
\beta(\theta, \lambda, r)=\frac{1}{2}\left[\left|S_{1}(\theta)\right|^{2}+\left|S_{2}(\theta)\right|^{2}\right]
$$

$$
\begin{aligned}
& S_{1}=\sum_{n=1}^{\infty} \frac{2 n+1}{n(n+1)}\left[\begin{array}{l}
a_{n}(x, m) \pi_{n}(\cos \theta) \\
+b_{n}(x, m) \tau_{n}(\cos \theta)
\end{array}\right] \\
& S_{2}=\sum_{n=1}^{\infty} \frac{2 n+1}{n(n+1)}\left[\begin{array}{l}
a_{n}(x, m) \tau_{n}(\cos \theta) \\
+b_{n}(x, m) \pi_{n}(\cos \theta)
\end{array}\right]
\end{aligned}
$$

In equation 13 and equation $14, a_{n}$ and $b_{n}$ are the angular dependent functions.

\section{Simulation results and discus- sion}

As displayed in Fig. 2, the scattering coefficients grow with increasing $\mathrm{Sr}_{2} \mathrm{Si}_{5} \mathrm{~N}_{8}: \mathrm{Eu}^{2+}$ phosphor concentration. It means that the whitelight quality can be enhanced by controlling $\mathrm{Sr}_{2} \mathrm{Si}_{5} \mathrm{~N}_{8}: \mathrm{Eu}^{2+}$ concentration. The scattering effects of both $\mathrm{Sr}_{2} \mathrm{Si}_{5} \mathrm{~N}_{8}: \mathrm{Eu}^{2+}$ and $\mathrm{SiO}_{2}$ particles are significantly affected by the optical properties of RP-WLEDs. The $\mathrm{Sr}_{2} \mathrm{Si}_{5} \mathrm{~N}_{8}: \mathrm{Eu}^{2+}$ phosphor has a higher absorption ability of the blue light from the LEDs. Therefore, the domination of emitted red light should be done for compensating red-light in RP-WLEDs. Besides, 5 wt. $\% \mathrm{SiO}_{2}$ concentration employed for enhancing scattering events, also increased the absorption ability of pc-LEDs. It is one 


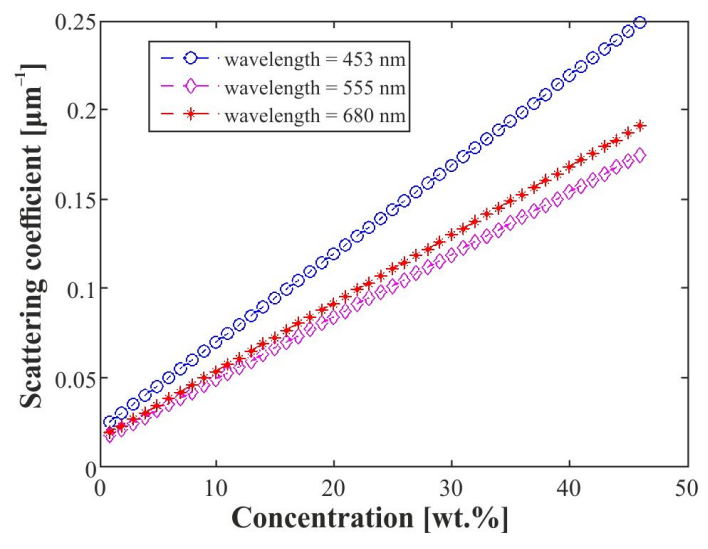

Fig. 2. Scattering coefficient versus $\mathrm{Sr}_{2} \mathrm{Si}_{5} \mathrm{~N}_{8}: \mathrm{Eu}^{2+}$ concentration at wavelengths of $453 \mathrm{~nm}, 555 \mathrm{~nm}$ and $680 \mathrm{~nm}$.

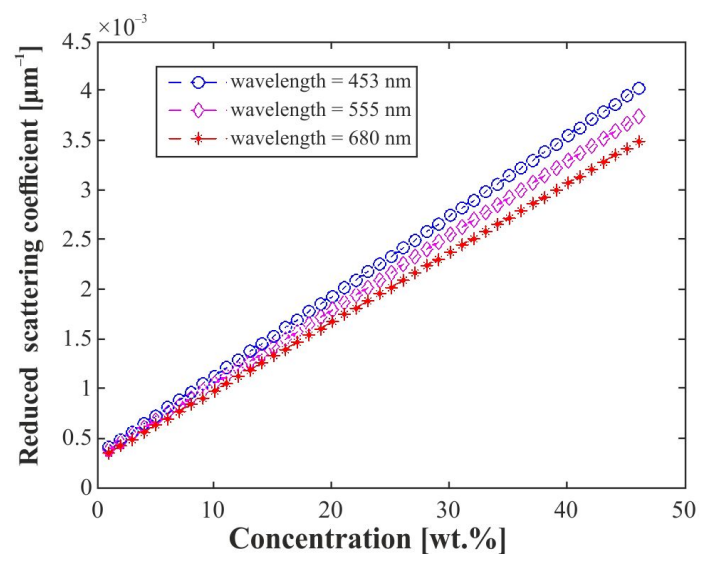

Fig. 3. Reduced scattering coefficient versus $\mathrm{Sr}_{2} \mathrm{Si}_{5} \mathrm{~N}_{8}: \mathrm{Eu}^{2+}$ concentration at wavelengths of $453 \mathrm{~nm}, 555 \mathrm{~nm}$ and $680 \mathrm{~nm}$.

of the reasons why $\mathrm{Sr}_{2} \mathrm{Si}_{5} \mathrm{~N}_{8}: \mathrm{Eu}^{2+}$ and $\mathrm{SiO}_{2}$ particles are used for producing white LEDs having high color quality.

The reduced scattering coefficient of $\mathrm{Sr}_{2} \mathrm{Si}_{5} \mathrm{~N}_{8}: \mathrm{Eu}^{2+}$ at wavelengths of $453 \mathrm{~nm}$, $555 \mathrm{~nm}$ and $680 \mathrm{~nm}$ are close to each other (Fig. 3). It indicates that the scattering stability of $\mathrm{Sr}_{2} \mathrm{Si}_{5} \mathrm{~N}_{8}: \mathrm{Eu}^{2+}$ is useful for controlling the color quality of RP-WLEDs. On the other hand, the angular scattering amplitudes of $\mathrm{Sr}_{2} \mathrm{Si}_{5} \mathrm{~N}_{8}: \mathrm{Eu}^{2+}$ have also been computed by MATLAB program. The results indicate that $\mathrm{Sr}_{2} \mathrm{Si}_{5} \mathrm{~N}_{8}: \mathrm{Eu}^{2+}$ particles have a significant advantage in producing blue light. The more blue light emitted, the more the yellow ring phenomenon reduced. These calculations and analysis can apparently be used to verify the results in Fig. 4 and Fig. 5.

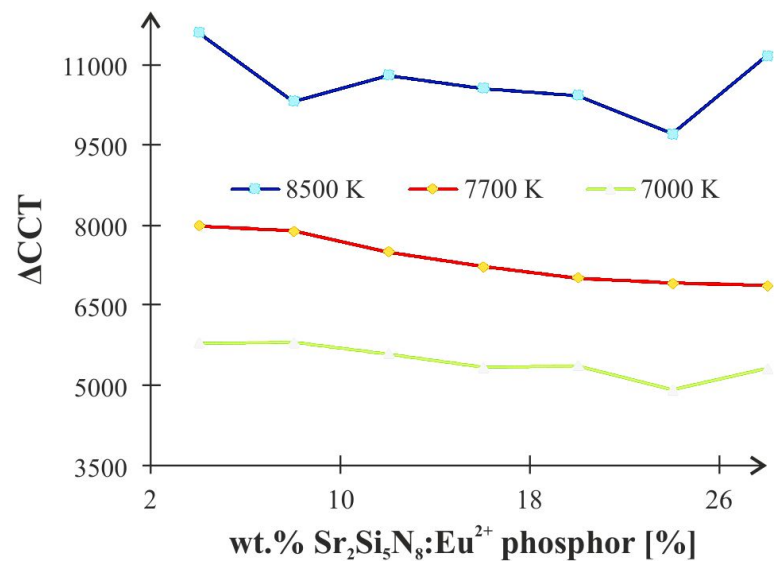

Fig. 4. The $\triangle C C T$ deviation of WLEDs by adding $\mathrm{SiO}_{2}$ and $\mathrm{Sr}_{2} \mathrm{Si}_{5} \mathrm{~N}_{8}: \mathrm{Eu}^{2+}$ phosphor particles at different temperatures.

Using a commercial program LightTools and varying the concentration of $\mathrm{Sr}_{2} \mathrm{Si}_{5} \mathrm{~N}_{8}$ : $\mathrm{Eu}^{2+}$ phosphor particles from $4 \%$ to $28 \%$, the $\Delta \mathrm{CCT}$ of WLEDs at $8500 \mathrm{~K}, 7700 \mathrm{~K}, 7000 \mathrm{~K}$ are shown in Fig. 4. On the other hand, Fig. 5 shows the influence of particle concentration on CRI. From these results it is seen that CRI remarkably increased when the concentration of $\mathrm{Sr}_{2} \mathrm{Si}_{5} \mathrm{~N}_{8}: \mathrm{Eu}^{2+}$ phosphor rose continuously from $4 \%$ to $28 \%$. The highest value of CRI was about 84 at $28 \% \mathrm{Sr}_{2} \mathrm{Si}_{5} \mathrm{~N}_{8}: \mathrm{Eu}^{2+}$ phosphor concentration. From Fig. 4 it is seen that the $\triangle \mathrm{CCT}$ of WLEDs decreased significantly by increasing concentration of $\mathrm{Sr}_{2} \mathrm{Si}_{5} \mathrm{~N}_{8}: \mathrm{Eu}^{2+}$ phosphor particles and achieved the lowest value at $28 \% \mathrm{Sr}_{2} \mathrm{Si}_{5} \mathrm{~N}_{8}: \mathrm{Eu}^{2+}$ phosphor. The scattered light of each particle in PC-LEDs is different, which results from the varying optical properties of WLEDs. In this situation, the CCT deviation can be reduced significantly in connection with enhanced scattering of blue light inside the phosphor compound.

\section{Conclusions}

The influence of the scattering of $\mathrm{SiO}_{2}$ and $\mathrm{Sr}_{2} \mathrm{Si}_{5} \mathrm{~N}_{8}: \mathrm{Eu}^{2+}$ phosphor particles on CCT deviation and CRI of WLEDs was analyzed 


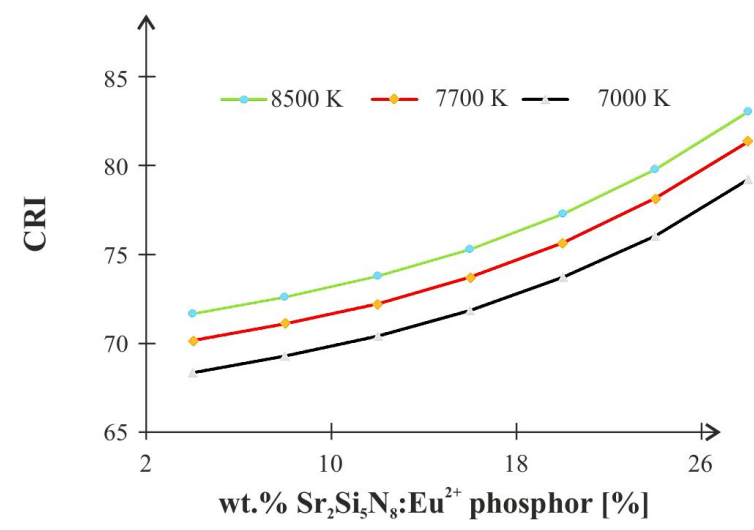

Fig. 5. CRI of RP-WLEDs as a function of $\mathrm{Sr}_{2} \mathrm{Si}_{5} \mathrm{~N}_{8}: \mathrm{Eu}^{2+}$ concentration.

and demonstrated. From the results and theory analysis, some conclusions are proposed:

(1) color uniformity (CCT deviation) significantly decreased with a rising concentration of $\mathrm{Sr}_{2} \mathrm{Si}_{5} \mathrm{~N}_{8}: \mathrm{Eu}^{2+}$ phosphor particles,

(2) CRI significantly increased, when the concentration of $\mathrm{Sr}_{2} \mathrm{Si}_{5} \mathrm{~N}_{8}: \mathrm{Eu}^{2+}$ phosphor rose continuously from $4 \%$ to $28 \%$. The highest value of CRI was 84 at $28 \% \mathrm{Sr}_{2} \mathrm{Si}_{5} \mathrm{~N}_{8}: \mathrm{Eu}^{2+}$ phosphor concentration.

This study provided a technical implication for WLEDs manufacturing and material development for their potential applications.

\section{References}

[1] Guan A., Mo F., Chen P., Geng Y., Chen Q., Zhou L., J. Disp. Technol., 12 (2016), 200.
[2] LAW T.K., IEEE T. Device Mat. Re., 16 (2016), 576.

[3] Santa C., Roy T., Majumder K., Yadav A., J. Exp. Nanosci., 9 (2014), 776.

[4] Markus S., Rosenthal T., Oecklera O., SCHNICK W., Crit. Rev. Solid State, 39 (2014), 215.

[5] LiU L., Xie J., Hirosaki N., Takeda T., Zhang C., Li J., Sun X., Sci. Technol. Adv. Mat., 12 (2011), 034404.

[6] Shuai Y., He Y., Tran N.T., Shi F.G., IEEE Photonic. Tech. L., 23 (2011), 137.

[7] Yu H., Zi W., Lan S., Zou H., Gan S., Xu X., Hong G., Mater. Res. Innov., 16 (2012), 298.

[8] Quoc A.N.D., LAI M.F., MA H.Y., LEE H.Y., J. Chin. Inst. Eng., 38 (2015), 297.

[9] Lai M. F., Quoc A.N.D., Ma H.Y., LeE H.Y., J. Chin. Inst. Eng., 39 (2016), 468.

[10] Ying S., ShIU A., Appl. Optics, 54 (2015), 28.

[11] Li C., RaO H., Zhang W., Zhou C., Zhang Q., Zhang K., J. Disp. Technol., 12 (2016), 255.

[12] Kim J.K., Luo H., Schubert E.F., Cho J., Sone C., Park Y., J. Appl. Phys., 44 (2005), 649.

[13] Luong D., Zhang W., LeE H., J. Alloy. Compd., 509 (2011), 7525.

[14] Piao X., Horikawa T., Hanzawa H., Machida K., Appl. Phys. Lett., 88 (2006), 219.

[15] Hayk N., Won H.I., Won C.W., Chem. Commun., 47 (2011), 43.

[16] Zhang B., Wang J, Hao L., Xu X., Agathopoulos S., Yin L., Wang C., Hintzen H., J. Am. Ceram. Soc., 100 (2016), 257.

[17] Zhong J., XIE M., Ou Z., Zhang R., Huang M., ZHAO F., In Proceedings of Symposium on Photonics and Optoelectronics (2011), Wuhan, 2011, 1.

[18] TAPANINEN O., $17^{\text {th }}$ International Conference on Thermal, Mechanical and Multi-Physics Simulation and Experiments in Microelectronics and Microsystems, Montpellier, 2016.

Received 2017-01-05

Accepted 2018-05-05 